Estudios Constitucionales, Año 10, No 2, 2012, pp. 369 - 390.

ISSN 0718-0195

Centro de Estudios Constitucionales de Chile Universidad de Talca

"Mutación constitucional y concreción normativa: cómo la estructura de la norma se relaciona con los cambios informales de la Constitución"

Adriano Sant'Ana Pedra

\title{
MUTACIÓN CONSTITUCIONAL Y CONCRECIÓN NORMATIVA: CÓMO LA ESTRUCTURA DE LA NORMA SE RELACIONA CON LOS CAMBIOS INFORMALES DE LA CONSTITUCIÓN
}

\author{
CONSTITUTIONAL MUTATION AND NORMATIVE CONCRETION: \\ HOW THE STRUCTURE OF THE NORM IS RELATED TO INFORMAL \\ CHANGES OF THE CONSTITUTION
}

\author{
Adriano Sant'Ana Pedra* \\ Profesor de la Facultad de Derecho de Vitória \\ adrianopedra@fdv.br
}

RESUMEN: Las normas constitucionales no se confunden con el texto de la Constitución. Ellas son el resultado de un proceso de concreción estructurado metodológicamente. De acuerdo con la teoría de la concreción, las normas constitucionales resultan de la conexión entre el "programa normativo" (Normprogram), que está asociado a la expresión literal, y el "ámbito normativo" (Normbereich), entendido como la realidad circundante, lo que resulta en la "norma de decisión". Bajo el marco de esta metodología, es posible constatar que las mutaciones constitucionales ocurren a partir de las alteraciones habidas en el "ámbito de la norma" y deben ser permitidas por el proceso de concreción.

ABSTRACT: Constitutional text and constitutional norm are not the same thing. Constitutional norm derives from a process of concretion, methodically structured. According to the concretion theory, constitutional norm results from the connection between the "normative program" (Normprogram), which is associated with the literal expression, and the "normative ambit" (Normbereich), understood as the surrounding reality, thus resulting in the "decision norm". Under the framework of this methodology, it is possible to verify that constitutional mutations occur from changes taken place in the "normative ambit" and must be allowed by the process of concretion.

PALABRAS CLAVE: concreción constitucional; interpretación constitucional; mutación constitucional.

KEYWORDS: constitutional concretion; constitutional interpretation; constitutional mutation.

* Doctor en Derecho Constitucional (Pontificia Universidad Católica de São Paulo-PUC/SP), Máster en Derechos y Garantías Fundamentales (Facultad de Derecho de Vitória), Profesor de la Facultad de Derecho de Vitória FDV en los cursos de pregrado y posgrado (maestría y doctorado), Profesor de la Escuela de la Magistratura del Estado de Espírito Santo - EMES, Procurador Federal de Abogacía General de la Unión (Brasil). adrianopedra@fdv.br adriano@pedra.adv.br. Artículo presentado el 12 de abril de 2012 y aceptada su publicación el $1^{\circ}$ de agosto de 2012. 


\section{INTRODUCCIÓN}

Es importante comprender que toda interpretación ocurre en un determinado contexto, que no puede ser desconsiderado. En verdad, no hay texto sin contexto. La Constitución y la realidad social siempre se buscan. La realidad fáctica y la realidad normativa se encuentran en una relación de reciprocidad, y no es posible separarlas, pues se encuentran mutuamente imbricadas.

La mutación constitucional es un proceso informal que cuida de la alteración de la Constitución. En la mutación, la norma constitucional se modifica a pesar de la permanencia de su texto, lo que presupone la no identificación entre la norma y el texto. El texto es compuesto por palabras cuyos significados no son únicos y aún son cambiantes con el pasar del tiempo. Lo que importa saber, entonces, es cómo las normas constitucionales pueden ser modificadas informalmente, en razón de las mudanzas habidas en la sociedad.

En este estudio se recorren las bases de la teoría de la concreción. Se constata que el proceso interpretativo no es solo cognitivo, sino fundamentalmente volitivo. En el paradigma actual, existe la superación de una concepción tradicional, donde la interpretación era comprendida apenas como un develamiento del sentido normativo, para otra concepción, en la cual se verifica un proceso creativo de producción de la norma, o sea, lo que se tiene es una atribución y no un develamiento de un significado preexistente en el enunciado lingüístico. Esto ocurre porque, como en cualquier proceso del conocimiento, la relación sujeto-objeto viene condicionada por la actuación recíproca de uno sobre el otro.

En este sentido, es imprescindible hacer la distinción entre texto normativo y norma. La estructura de la norma constitucional se presenta determinada por el programa de la norma y por el ámbito de la norma, y la conexión entre ambos vendrá a resultar en la norma de decisión. Todo este análisis permite constatar la relación existente entre concreción y mutación constitucional y cómo las normas constitucionales son modificadas informalmente de acuerdo a la realidad social.

\section{TEXTO NORMATIVO Y NORMA}

Para que la Constitución sea aplicada, es necesario hacer la interpretación de su texto normativo, de donde será extraída la norma jurídica. De la inter- 
pretación de los textos resultan las normas. Texto y norma no se identifican. La norma es la interpretación del texto normativo ${ }^{1}$.

A pesar de la existencia de una relación mutua entre el texto normativo y la norma, no hay una correspondencia biunivoca entre ambos ${ }^{2}$. Es posible haber (a) disyunción de normas, cuando un enunciado puede expresar una u otra norma; (b) conjunción de normas, cuando un enunciado puede expresar varias normas conjuntamente; $(c)$ sobreposición de normas, cuando dos enunciados pueden expresar normas que se sobreponen parcialmente; (d) enunciado sin norma, cuando un enunciado no es apto para expresar una norma; y $(e)$ norma sin enunciado, cuando no hay cualquier enunciado o combinación de enunciados que impliquen en una norma, que es producida por el derecho mediante concretización ${ }^{3}$, de lo que se concluye que es posible extraer norma incluso cuando no existe texto ${ }^{4}$.

El texto constituye el punto de partida para la formación de las significaciones y, al mismo tiempo, para la referencia de los significados. Las normas resultan de la interpretación de los textos y interpretar es atribuir valores a los símbolos, esto es, adjudicarles significaciones y, por medio de esas, referencias a objetos 5 . Se puede decir aún que interpretar, en general, consiste en reconocer o atribuir un significado o un sentido a ciertos signos o símbolos ${ }^{6}$, o, en otras palabras, que interpretar la Constitución es conocerla, no sólo su letra, sino también su espíritu, en sus significados más profundos y en su verdadero alcance ${ }^{7}$.

De esa manera, las normas no son textos ni el conjunto de ellos, sino los sentidos construidos a partir de la interpretación sistemática de textos normativos. De allí que se afirma que los dispositivos se constituyen en objeto de la interpretación; y las normas en su resultado ${ }^{8}$. La interpretación del Derecho es la operación intelectiva por medio de la cual, a partir del lenguaje vertido en

${ }^{1}$ Grau (2006), p. 27.

${ }^{2}$ Guastini (2005), p. 34.

${ }^{3}$ Gomes Canotilho (2002), pp. 1187-1190.

${ }^{4}$ Sant'Ana Pedra (2008c), p. 19.

5 Barros de Carvalho (2006), p. 62.

${ }^{6} \mathrm{VIGO}(2004)$, p. 13.

7 Cunha Ferraz (1986), p. 22.

8 Ávila (2007), p. 30. 
disposiciones (enunciados) con fuerza normativa, el operador del Derecho llega a determinado y específico contenido?.

El texto no existe en sí mismo. El texto no tiene control absoluto sobre la interpretación que le será dada. La norma es constituida por el intérprete, en el trascurso del proceso de concreción del derecho ${ }^{10}$, o sea, concreción de la norma es construcción de la norma ${ }^{11}$. La norma jurídica sólo se mueve ante un hecho concreto, por la acción del aplicador del derecho, que es el intermediario entre la norma y los hechos de la vida.

Por otro lado, el intérprete constitucional no puede dar sentido de forma arbitraria a los textos, pues texto y norma no están separados ${ }^{12}$. Texto normativo y norma son cosas distintas, mas no separadas -en el sentido de que uno pueda existir sin el otro. En este sentido Karl Engisch destaca que la concreción del derecho significa orientación del derecho a lo real y no la "imposición del derecho a la realidad y tendencia a una realidad a estructurar" 13 .

Así, el intérprete no debe "extraer" el sentido que estaría "contenido" en el texto, pues los sentidos no están acoplados al texto, listos para ser desacoplados como quería la hermenéutica clásica y como quiere, aún hoy, buena parte de los juristas que buscan la inserción en ese complejo terreno que es la hermenéutica ${ }^{14}$.

Algunos estudiosos ven en la interpretación un carácter puramente cognoscitivo. Pero otra corriente del pensamiento, la cual es adoptada en este estudio, entiende que la interpretación implica un juicio decisorio, dentro de una esfera de decisiones viables ${ }^{15} \mathrm{y}$, por eso, la interpretación del derecho es constitutiva y no meramente declaratoria.

$\mathrm{Y}$, como la interpretación es una elección entre varias opciones ${ }^{16}$, la interpretación sólo puede ser considerada como siendo la más adecuada dentro de un dado contexto. En ese sentido, el caso concreto gana relevo ${ }^{17}$, pues refleja una

9 Ramos Tavares (2007), p. 77.

${ }^{10}$ Grau (2006), p. 29.

${ }^{11}$ Múller (2008), p. 231.

12 Sant'Ana Pedra (2008b), p. 12.

13 ENGISCH (2004), p. 177.

${ }^{14}$ STRECK (2004), p. 153.

15 Ribeiro Bastos (2002), p. 263.

${ }^{16}$ Ribeiro Bastos y Meyer-Pflug (2007), p. 155.

17 Sant'Ana Pedra (2008b), p. 9. 
nueva situación en que el intérprete jurídico tiene que renovar la efectividad de la norma. Según Hans-Georg Gadamer, el intérprete jurídico no puede sujetarse a la intención de los que elaboraron la ley. Por el contrario, está obligado a admitir que las circunstancias fueron siendo mudadas y que, por lo consiguiente, tiene que determinar de nuevo la función normativa de la ley ${ }^{18}$.

Esto ocurre porque la interpretación no persigue el sentido, sino uno de los sentidos, el cual deberá ser contextualmente posible y adecuado. Esa posibilidad de múltiples interpretaciones viabiliza la evolución de la norma aun cuando el texto permanezca.

\section{CONCRECIÓN CONSTITUCIONAL}

El carácter abierto y amplio de la Constitución exige mayor atención a la interpretación constitucional. La hermenéutica enseña al intérprete que las directivas de acción y las proposiciones valorativas, contenidas en los preceptos jurídicos, sólo pueden ser cabalmente comprendidas e inteligidas cuando se aplican a situaciones concretas ${ }^{19}$.

Como destaca Konrad $\mathrm{Hesse}^{20}$, la interpretación es fundamental para el derecho constitucional, pues, en razón del carácter abierto y amplio de la Constitución, los problemas de interpretación surgen con mayor frecuencia en éste que en otros sectores del ordenamiento jurídico cuyas normas son más detalladas.

Todas estas características de las normas constitucionales exigen que la actividad del intérprete ocurra en el campo de la "nueva hermenéutica" constitucional. En este sentido, la concreción ${ }^{21}$ normativa es una exigencia de la abertura constitucional.

La Constitución abierta es una característica de las sociedades complejas, porque, delante de la multiplicidad de los problemas que pueden surgir, la Constitución necesita de soluciones para acompañar este casuístico problemático y, por eso, el contenido de esas normas necesita ser objeto de concreción ${ }^{22}$. Para Konrad Hesse,

\footnotetext{
${ }^{18}$ Gadamer (1999), p. 485.

${ }^{19}$ Queiroz (2000), p. 151.

${ }^{20}$ Hesse (1992), p. 34.

${ }^{21}$ Debe registrarse aquí la necesidad de distinguir entre concreción (o concretización) y eficacia social o eficacia jurídica. Cf. Adeodato (2006), p. 245.

22 Sant'Ana Pedra (2011), p. 236.
} 
la interpretación constitucional es "concretización" (Konkretisierung). Precisamente lo que no aparece de forma clara como contenido de la Constitución es lo que debe ser determinado mediante la incorporación de la "realidad" de cuya ordenación se trata. En este sentido la interpretación constitucional tiene carácter creativo: el contenido de la norma interpretada sólo queda completo con su interpretación; ahora bien, sólo en ese sentido posee carácter creativo: la actividad interpretativa queda vinculada a la norma ${ }^{23}$.

Mientras en la hermenéutica tradicional la interpretación era comprendida apenas como el develamiento del sentido del texto normativo, en la concreción el proceso interpretativo no es tan sólo cognitivo, sino fundamentalmente volitivo, creativo ${ }^{24}$. En este sentido el derecho es esencialmente voluntarista, vale decir, necesita de la voluntad del intérprete ${ }^{25}$.

La concreción es la propia elaboración de una norma jurídica general que no existe (aún) antes del caso concreto. En virtud de eso, es posible decir que toda concreción constitucional es perfeccionadora y creativa ${ }^{26}$ y que la norma es construida, por el intérprete, en el proceso de concretización del derecho ${ }^{27}$. Así, de acuerdo con la teoría estructurante del derecho, la concreción quiere decir la producción de una norma jurídica general en el marco de la solución de un caso determinado ${ }^{28}$.

Por eso Friedrich Müller dice que la teoría estructurante del derecho no es sólo una nueva concepción, sino que además es una concepción innovadora de la teoría del derecho. Ella resulta, por primera vez, de un concepto pos-positivista de norma jurídica ${ }^{29}$. La norma jurídica no más se encuentra lista en los textos normativos, pero solamente será producida en cada proceso particular de solución jurídica de un caso. Así, escribe Friedrich Müller:

"Concretizar" no significa aquí, por lo consiguiente, a la manera del positivismo antiguo, interpretar, aplicar, subsumir silogísticamente y concluir. Tampoco, como en el positivismo sistematizado de la última fase de Kelsen, "individualizar"

\footnotetext{
${ }^{23}$ Hesse (1992), pp. 40-41.

${ }^{24}$ Ramos Tavares (2006), p. 60.

25 Ribeiro Bastos (2002), p. 47.

${ }^{26}$ Bonavides (2003), p. 504.

${ }^{27}$ Grau (2006), pp. 77-78.

${ }^{28}$ Alflen da Silva (2000), p. 422.

${ }^{29}$ MÜller (2007), p. 161.
} 
una norma jurídica genérica codificada en la dirección del caso individual "más restricto". Muy por el contrario, "concretizar" significa: producir delante de la provocación por el caso de conflicto social, que exige una solución jurídica, la norma jurídica defendible para ese caso en el marco de una democracia y de un Estado de Derecho ${ }^{30}$.

A pesar de la pretensión de sucesión del término “interpretación” por el término "concreción" (o "concretización”), como desea Friedrich Müller, es posible continuar el empleo del término interpretación, siempre que sea comprendido en su sentido "moderno", de concreción, en oposición al tradicional ${ }^{31}$.

La metódica estructurante de Friedrich Müller es formada por tres elementos, a saber: (i) el programa normativo, (ii) el ámbito normativo y (iii) la norma de decisión. Según el método concretista ${ }^{32}$ de Friedrich Müller ${ }^{33}$, hay una superación de la tensión dialéctica entre conservación de la Constitución formal y mutación, no existiendo identidad entre la norma y el texto de la norma.

Siempre que los juristas hablan y escriben acerca de "la" Constitución entienden por tal el texto de ésta; cuando hablan de "la" ley entienden por tal su tenor literal. Por el contrario, la nueva dirección que ha tomado la hermenéutica jurídica ha llevado a destacar la realidad fundamental de la diferencia entre norma y texto de la norma. El tenor literal de una prescripción de Derecho positivo resulta ser tan sólo la "punta del témpano" 34 .

La teoría estructurante del derecho considera como normativos aquellos elementos que confieren una dirección al proceso decisorio, o sea, elementos sin los cuales el caso sería decidido de manera diferente. Esos elementos constituyen el programa de la norma (datos lingüísticos) y el ámbito de la norma (datos reales).

\footnotetext{
30 MÜller (2007), p. 150.

31 Ramos Tavares (2008), p. 16.

32 En las palabras del propio autor, "se puede decir, en caso que se quiera, 'concretista'. Eso expresa, creo yo, lo mismo que cuando llamé mi Teoría y metódica del derecho de 'realista'.” Cf. Müller (2007), p. 271.

33 Paulo Bonavides escribe que el método concretista de Friedrich Müller "tiene su base medular o inspiración mayor en la tópica”. Cf. Bonavides (2003), p. 498. Pero el propio Friedrich Müller contesta esta visión: "no estoy de acuerdo con Paulo Bonavides cuando él afirma poseer mi posición una ‘inspiración tópica’” Cf. Müller (2007), p. 272.
}

${ }^{34}$ MÜller (2006), p. 235. 
El programa normativo representa el análisis del texto normativo (elemento lingüístico). El programa normativo es el resultado de la interpretación del texto normativo, o sea, lo que es expresado por el tenor literal bien como todos los recursos interpretativos auxiliares, y se forma a partir de los datos de la lengua. Así, para Friedrich Müller,

el programa normativo es elaborado por medio de todas las determinantes de la concreción de las leyes, reconocidas como legítimas, como tratamiento del texto de la norma desde las ya mencionadas interpretaciones gramaticales, genéticas, históricas y sistemáticas, hasta las figuras interpretativas específicas de las grandes áreas del derecho penal, del derecho civil, de la historia del derecho y del derecho comparado ${ }^{35}$.

Como se trata de uno de los elementos que se destinan a alcanzar la norma de decisión, el programa de la norma constituye un resultado intermediario y provisorio de la interpretación de todos los datos lingüísticos ${ }^{36}$.

El ámbito normativo (o dominio normativo) engloba las interferencias provocadas en la norma por la realidad (elemento empírico). Se trata de un concepto $^{37}$ a ser determinado estructuralmente y se refiere a las partes integrantes de la normatividad que son co-constitutivas de la norma. Según la lección de Friedrich Müller, el ámbito normativo es

el segmento de la realidad social en su estructura fundamental que para sí ha "escogió" el programa de la norma como su ámbito de regulación o ha creado parcialmente desde el principio (como sucede en gran parte con las prescripciones relativas a las formalidades y con otras similares). El ámbito de la norma puede estar engendrado por el Derecho (prescripciones acerca de plazos, términos, formalidades, reglas acerca de instituciones y de procedimiento, etc.) o no estarlo ${ }^{38}$.

\footnotetext{
${ }^{35}$ Müller (2007), p. 224.

${ }^{36}$ Müller (2007), p. 162.

37 Sobre las dificuldades de comprensión del concepto de "ámbito de la norma", ver AfONSO DA SiLva (2009), p. 87, que escribe: "No es tarea fácil entender exactamente la forma como la 'realidad social' es introducida en la aplicación del derecho según la teoría de Müller, o sea, cuáles serían exactamente el concepto y la aplicación del llamado 'ámbito de la norma', que diferenciaría su teoría de otras teorías del derecho".
}

${ }^{38}$ MÜller (2006), p. 241. 
Aclara además Friedrich Müller ${ }^{39}$ que el ámbito normativo no es un conglomerado de hechos materiales, sino una conexión de elementos estructurantes extraídos de la realidad social a partir de la perspectiva selectiva y valorativa del programa de la norma. El ámbito de la norma está formado por la influencia de la perspectiva valorativa del programa de la norma a partir del ámbito material o del ámbito del caso. En estos términos, Marcelo Neves anota que el ámbito de la norma importa una función selectiva ante los ámbitos de la materia y del caso $^{40}$. El ámbito material designa la totalidad de las hipótesis sobre la cuestión de hecho inicialmente introducidas de forma asociativa para fines de narrativa del caso. Además, el ámbito del caso representa un recorte de este ámbito material. Así, de acuerdo con Friedrich Müller, con la distinción entre ámbito material y ámbito de la norma queda descartada la fuerza normativa de lo fáctico como usurpación de la eficacia normativa por parte de meros hechos ${ }^{41}$. En el Estado Democrático de Derecho, no puede existir la fuerza normativa de lo fáctico, mas sólo hechos relevantes para el programa de la norma y conformes al programa de la norma pueden co-determinar el contenido de la decisión ${ }^{42}$.

Saber hasta qué punto la interpretación y la aplicación del derecho pueden apoyarse en la facticidad social y en resultados de la pesquisa sociológica -sin errar el blanco de la normatividad del derecho- debe visto como un problema de metodología jurídica. Friedrich Müller advierte que aspectos de la realidad social sólo pueden entrar en la dogmática y metódica jurídicas en el interés de la normatividad jurídica, a servicio de la racionalidad específicamente jurídica en vinculación a la norma ${ }^{43}$.

Esta visión supera aquella kelseniana, para la cual "derecho y realidad, norma y segmento normatizado de la realidad aparecen yuxtapuestos 'en si' sin que se relacionaren" ${ }^{\prime 4}$, como resalta Friedrich Müller. En la perspectiva kelseniana, uno no precisa del otro y ambos sólo se encuentran en el camino de la subsunción del soporte fáctico, de una aplicación de la prescripción.

${ }^{39}$ MÚller (1989), p. 123.

${ }^{40}$ Neves (2007), p. 85.

${ }^{41}$ Müller (2007), p. 30.

${ }^{42}$ MÜller (2007), p. 154.

${ }^{43}$ Müller (2008), p. 35. Ver también: Mưller (2007), p. 58.

${ }^{44}$ Müller (2008), p. 18. Ver también: Mưller (2007), p. 42. 
El método normativo-estructurante presupone la existencia de una implicación necesaria entre el programa normativo y el ámbito normativo, o sea, un nexo entre los preceptos jurídicos y la realidad que ellos intentan regular, una vinculación tan estricta que la propia normatividad, tradicionalmente vista como atributo esencial de los comandos jurídicos, parece haberse evadido de los textos para buscar apoyo fuera del ordenamiento ${ }^{45}$. La estructura de la norma señala la conexión entre el programa de la norma y el ámbito de la norma y, por eso, la norma sólo puede comprenderse como una articulación de estas dos dimensiones ${ }^{46}$.

En la decisión, siempre se tiene la posibilidad de optar entre alternativas semánticas distintas, pero esa posibilidad necesita satisfacer las particularidades y las exigencias normativas de cada caso concreto. Se puede decir, así, que la interpretación del derecho no es una actividad del conocimiento, sino constitutiva, y, por lo tanto, decisoria ${ }^{47}$; pues la norma objeto de la interpretación no se confunde con el texto, sino se presenta como resultado de un trabajo de construcción.

La norma de decisión constituye la solución del problema concreto presentado, dentro de los parámetros jurídicos. En las palabras de Friedrich Müller, "la norma de decisión es el estado de agregación más individualizado de la norma jurídica, y no una entidad autónoma situada al lado de ella” ${ }^{*}$. Y más aún agrega:

La concreción es, realísticamente considerada, la construcción de la norma jurídica en el caso concreto. La norma jurídica no existe, como vimos, ante casum, sino se construye in casu. La norma es la formulación general de la decisión jurídica; la formulación individual (esto es, el tenor de la decisión) se llama norma de decisión ${ }^{49}$.

La concreción implica un caminar del texto de la norma para la norma concreta. La concreción se realiza en el paso siguiente, cuando es creada la norma de decisión, apta a dar solución al caso concreto. "Por eso dicen algunos autores que interpretación y concreción son distintas entre sí -a lo que contesto, para

\footnotetext{
45 Ferreira Mendes et al (2008), p. 106.

46 Gomes Canotilho (2002), p. 1200.

${ }^{47}$ Grau (2006), p. 66.

${ }^{48}$ MÚller (2008), p. 148.

${ }^{49}$ MÜller (2007), p. 162.
} 
sustentar que no existe, hoy, interpretación del derecho sin concreción. Esta es, pues, la última etapa de aquélla" ${ }^{50}$.

\section{ConCRECIÓN Y MUTACIÓN CONSTITUCIONAL}

Muchas normas constitucionales presentan un elenco de posibilidades semánticas y, como dice Laurence H. Tribe, "los jueces deben entonces hacer escogencias entre las diferentes interpretaciones de la Constitución" ${ }^{\prime 1}$. Eso sucede porque el texto prevé varias opciones a ser utilizadas en el momento de la aplicación de la Constitución y las circunstancias de cada caso concreto van a determinar cual, entre esas opciones semánticas, debe ser utilizada por el intérprete ${ }^{52}$.

El intérprete tiene presente los diferentes significados posibles de un texto y busca encontrar aquel que sería más adecuado al caso presentado. Karl Larenz escribe que el intérprete hace una opción "entre diferentes posibilidades de interpretación. 'Interpretar' un texto quiere decir, por lo tanto, decidirse por una entre muchas posibles interpretaciones" ${ }^{53}$. A este respecto, anota Jerzy Wróblewski:

No hay más razones teóricas para sustentar la tesis de la única interpretación correcta en el dominio de las reglas constitucionales que las existentes para otras reglas legales y en favor de esa tesis funcionan las mismas razones ideológicas. El conocimiento de las razones teóricas para rechazar la tesis en cuestión permite una clara visión de la relevancia general de las decisiones interpretativas en lo que concierne a las reglas constitucionales ${ }^{54}$.

La multiplicidad semántica no trae consigo los criterios necesarios para hacer una elección metódica normativamente adecuada. Y, como la normatividad surge tan sólo en el proceso de concreción, la mutación constitucional pasa a ser vista como una dimensión de la realización de la norma. En ese sentido, toda norma sería esencialmente mutante ${ }^{55}$.

${ }^{50}$ Grau (2006), pp. 29 y 79.

${ }^{51}$ Tribe (1986), p. vii.

52 Almeida Filho (2008), p. 189.

${ }^{53}$ LARENZ (1997), p. 283.

${ }^{54}$ WróblewsKi (1985), p. 91.

55 Sant'Ana Pedra (2005), p. 156. 
La "concretización" del contenido de una norma constitucional, así como su realización, sólo resultan posibles incorporando las circunstancias de la "realidad" que esa norma está llamada a regular. Las singularidades de estas circunstancias -con frecuencia conformadas ya jurídicamente-integran el "ámbito normativo", el cual, a partir del conjunto de los datos del mundo social afectados por un precepto, y a través del mandato contenido sobre todo en el texto de la norma, el "programa normativo" es levado a parte integrante del contenido normativo. Puesto que estas singularidades, y con ellas el "ámbito normativo", se hallan sometidas a cambios históricos, los resultados de la "concretización" de la norma pueden cambiar, a pesar de que el texto de la norma (y con ello, en lo esencial, el "programa normativo") continúa siendo idéntico. De todo ello resulta una mutación constitucional constante, más o menos notable, que no resulta fácil de captar y que, por ello, rara vez se manifiesta con nitidez ${ }^{56}$.

Se constata así el fenómeno de las mutaciones constitucionales como una constante en la vida de los Estados, y las constituciones, como organismos vivos que son, acompañan la evolución de las circunstancias políticas, económicas ${ }^{57}$ y sociales ${ }^{58}$.

La mutación constitucional parte del presupuesto básico indispensable de que es preciso que exista una norma constitucional debidamente concretizada para que ésta sea objeto de mutación. En otras palabras, las mutaciones constitucionales nada más son que las alteraciones semánticas de los preceptos de la Constitución ${ }^{59}$, en consecuencia de las modificaciones del punto de vista histórico-social o fáctico-axiológico en que se concretiza su aplicación ${ }^{60}$.

En este sentido, conviene traer un emblemático ejemplo de mutación constitucional que ocurrió en los Estados Unidos de América en razón de alteraciones históricas habidas en el ámbito de la norma.

La Constitución norteamericana (Enmienda XIV) establece que ningún Estado puede negar a cualquier persona bajo su jurisdicción igual protección de

\footnotetext{
${ }^{56}$ Hesse (1992), p. 28.

57 LammêGo Bulos (1997), p. 57.

${ }^{58}$ FABRIZ (2006), p. 18.

${ }^{59}$ Hay que distinguir aquí las mutaciones constitucionales típicas, que se producen debido a los cambios en la realidad circundante (ámbito normativo), y las mutaciones constitucionales atípicas, que pueden ser calificadas como un simple cambio de posición de la Corte, sea por el cambio en su composición sea por otro factor.

${ }^{60}$ Ferreira Mendes et al (2008), p. 130.
} 
las leyes ${ }^{61}$. En 1896, al juzgar el caso Plessy versus Ferguson ${ }^{62}$, la Suprema Corte hizo una concreción de la "cláusula de igual protección" de la Enmienda XIV, al entender que sería posible una separación igualitaria. Con eso, se estableció, en los Estados Unidos de América, la doctrina "separate but equal" ("separados pero iguales"), que vino a endosar la segregación racial practicada en diversos Estados norteamericanos.

Es necesario comprender el contexto en que la decisión del caso Plessy versus Ferguson fue tomada. Se debe destacar que la versión original de la Constitución norteamericana, de 1787, permitía al régimen de la esclavitud (sección 2 del artículo $1^{\circ}$ ) y la Suprema Corte llegó a negar la condición de ciudadano a un esclavo en el juicio del caso Dred Scott versus Sandford ${ }^{63}$, en 1857. Esta decisión contribuyó para irritar los ánimos entre los Estados del sur -esclavistas y agrarios-y los del norte -antiesclavistas e industriales-, lo que culminó en la Guerra Civil, también conocida como Guerra de Secesión. La decisión de la Suprema Corte también apresuró la abolición de la esclavitud en los Estados Unidos de América, lo que ocurrió en el año de 1865, con la Enmienda XIII. En aquella época, los negros eran largamente discriminados en la sociedad y la decisión

\footnotetext{
${ }^{61}$ In verbis: "[...] nor deny to any person within its jurisdiction the equal protection of the laws" ("[...] ni negar a cualquier persona en su jurisdicción la igual protección de las leyes").

${ }^{62}$ La Suprema Corte norteamericana entendió que la ley del Estado de Lousiana que determinaba vagones específicos para negros no contrariaba la Enmienda XIII (abolición de la esclavitud) ni la Enmienda XIV (igual protección de las leyes), porque esta ley estadual se basaba en la condición de igualdad entre blancos y negros, aunque que deberían permanecer separados. Según este entendimiento segregacionista, al disponer transporte a los negros en vagones de trenes iguales a los utilizados por los blancos, no había tratamiento desigual, razón por la cual sería posible apartarlos sin que hubiera violación de la Constitución norteamericana.

${ }^{63}$ El Congreso Nacional norteamericano aprobó, en 1850, el Missouri Compromise Act, que abolía la esclavitud en los nuevos territorios. Conviene recordar que, a mediados del siglo XIX, los Estados Unidos de América estaban en plena expansión territorial, sea por compra, guerra, anexión o conquista. Las nuevas tierras eran incorporadas en la condición de territorio federal y pasaban a la condición de Estado bajo el cumplimiento de ciertos requisitos. Y, como eran territorios federales, eran regidos por la legislación federal. En este escenario, el esclavo Dred Scott fue llevado por su señor del Estado de Missouri -donde la esclavitud era admitida- para territorio federal donde la esclavitud había sido abolida. En este territorio federal, Dred Scott pleiteó su libertad con base al citado Missouri Compromise Act. Pero el ChiefJustice Roger Taney decidió por la inconstitucionalidad de este acto legislativo federal que aseguraba la libertad de los negros en los nuevos territorios federales. La Suprema Corte entendió que el Congreso no tenía poderes para abolir la esclavitud y que un esclavo no podía ser considerado ciudadano, careciendo de legitimidad activa para pleitear en juicio su propia libertad. Abstrayéndose el contexto y la época en que fue proferida, esta decisión configura una página negativa en la historia de la Suprema Corte norteamericana.
} 
de la Suprema Corte en el caso Plessy versus Ferguson procuraba apartar blancos y negros con el fin de evitar la ocurrencia de mayores conflictos. En razón de eso -y sin valorar aquí los fundamentos de esta decisión-, la segregación racial ocurrió con la aquiescencia de los poderes estatales.

Pero con la evolución de la sociedad norteamericana y con la actuación de grupos de presión ${ }^{64}$, este escenario se modificó y, con él, el ámbito normativo, lo que hizo que también se modificase los resultados de la concreción. En este contexto, en 1954, al juzgar el caso Brown versus Board of Education of Topeka ${ }^{65}$, la Suprema Corte consideró inconstitucional la segregación racial en las escuelas de los Estados Unidos de América, en decisión que puso fin a la doctrina "separate but equal" y se tornó un marco en la política de integración racial. Sobre este caso, José Joaquim Gomes Canotilho escribe que

el problema que se debatió largamente en los tribunales americanos fue el de saber si el principio de la igual protección era compatible con la segregación racial en las escuelas públicas. La respuesta fue sí: es compatible con el principio de la igualdad la doctrina "separate but equal". Hasta que... Hasta que en el caso del epígrafe, el juez Warren registró en términos paradigmáticos un nuevo candidato positivo del corpus constitucional -la integración racial en las escuelas públicas como principio constitucional: "Nosotros concluimos que, en el campo de la enseñanza pública, no tiene lugar la doctrina 'separate but equal. Políticas educacionales segregacionistas son inherentemente desiguales" 66 .

La Corte Warren ${ }^{67}$ entendió que la doctrina "separate but equal” no se sustentaba, pues la segregación practicada en las escuelas no propiciaba a los niños del "grupo minoritario" las mismas oportunidades educacionales y, también,

\footnotetext{
${ }^{64}$ Conviene considerar el movimiento de los derechos civiles, liderado por Martin Luther King Jr. En este mismo contexto histórico, en diciembre de 1955, y bajo una legislación segregacionista, Rosa Parks fue presa en Montgomery, Alabama, Estados Unidos de la América, porque se negó a ceder su asiento en un autobús a un hombre blanco, lo que desencadenó un boicot al transporte público de aquella ciudad.

${ }^{65}$ Aunque hubiese escuelas más cerca de su casa, Linda Brown, niña negra de 8 años de edad, tenía que cruzar la ciudad de Topeka (Kansas) para asistir a las clases en una escuela pública. Las escuelas próximas a su casa no aceptaban a Linda Brown como alumna porque eran destinadas exclusivamente a niños de color blanco.

${ }^{66}$ Gomes Canotilho (2002), p. 1121.

${ }^{67}$ La Suprema Corte era así llamada porque era presidida por el Chief Justice Earl Warren (1953-1969). Es de la tradición del derecho constitucional norteamericano identificar nominalmente la Suprema Corte por su respectivo presidente.
} 
causaba a este grupo una sensación de inferioridad que le afectaba la motivación de aprender.

Ronald Dworkin anota que la Suprema Corte siguió la política del activismo en detrimento de la política de la moderación en casos como los que envuelven la segregación porque los términos de la cláusula de igual protección dejan abierta la cuestión de saber si las diferentes prácticas educacionales de los Estados violan o no la Constitución ${ }^{68}$. Bajo la vigencia de un mismo texto constitucional, el tratamiento dado a los negros evolucionó de una segregación para una no segregación, en razón de mudanzas históricas habidas en el contexto social norteamericano, que llevaron a creer que la segregación racial implica, necesariamente, una desigualdad, lo que es vedado por la propia Enmienda XIV.

Otro ejemplo de interés, ocurrido en derecho constitucional brasileño, bajo la vigencia de la Constitución anterior, se refiere a la posibilidad de corregir monetariamente las deudas de cualquier especie independientemente de previsión de ley. Fue a través de construcción pretoriana, anticipándose al legislador, que se dispensó la previa autorización legal para su aplicación. Esto ocurrió porque el fenómeno de la inflación impuso una nova visión acerca del principio de la legalidad, ocurriendo, así, una mutación constitucional ${ }^{69}$. En un primer momento, cuando la corrosión de la moneda no era extrema, el Supremo Tribunal Federal brasileño afirmaba que "la corrección monetaria solamente puede ocurrir con autorización legal"70. Sin embargo, más tarde, cuando el problema inflacionario se agravó, el Supremo Tribunal Federal pasó a entender que el principio de la legalidad no colide con la corrección monetaria sin ley expresa en los casos de deuda de valor ${ }^{71}$.

Otro ejemplo de mutación constitucional en el derecho brasileño se refiere a la interpretación del tratamiento que la Constitución da a la infidelidad partidaria. El razonamiento anterior del Supremo Tribunal Federal, expresado

\footnotetext{
${ }^{68}$ DWORKIN (1978), p. 137.

${ }^{69}$ Ferreira Mendes et al (2008), p. 230.

${ }^{70}$ Recurso Extraordinario RE 74.655. Supremo Tribunal Federal, Órgano juzgador: Segunda Turma, Relator Min. Bilac Pinto, Fecha decisión: 27/03/1973, DJ 01/06/1973. No obstante, el ministro relator hace la enmienda de que "tal regla, sin duda, comporta dos excepciones: cuando se trate da actualización de valores, en materia de accidente de trabajo o en los casos de responsabilidad civil, por accidente, cuando la indemnización tenga carácter alimentario".

${ }^{71}$ Recurso Extraordinario RE 104.930. Supremo Tribunal Federal, Órgano juzgador: Primera Turma, Relator Min. Rafael Mayer, Fecha decisión: 23/04/1985, DJ 10/05/1985.
} 
en las decisiones paradigmas proferidas en los mandatos de seguridad (mandados de segurança) MS 20.916 y yS 20.927 73 era que no había imposición de fidelidad partidaria para los detentores de cargos electivos. Sin embargo, el Supremo Tribunal Federal modificó su razonamiento anteriormente establecido y pasó a considerar constitucionalmente admitida la pérdida del mandato en virtud de infidelidad partidaria, lo que ocurrió en las decisiones proferidas en los mandatos de seguridad MS 26.602 ${ }^{74}$, MS 26.603 75 e MS 26.604 ${ }^{76}$. De acuerdo con este nuevo entendimiento del Supremo Tribunal Federal brasileño, el parlamentario infiel se podrá defender ante la Justicia Electoral, mas el tránsfuga perderá su mandato político en caso de que los motivos de su salida del partido no sean legítimos ${ }^{77}$.

En verdad, siempre hubo, en la Excelsa Corte brasileña, divergencias de pensamiento procedentes de diferentes interpretaciones que pueden ser extraídas a partir del texto constitucional ${ }^{78}$. Todavía, hoy en día, prevalece el entendimiento en favor de la fidelidad partidaria. Esta mudanza de entendimiento del Supremo Tribunal Federal puede ser atribuida no sólo porque su composición fue alterada, sino también, y principalmente, porque ocurrieron mudanzas en el ámbito de la norma ${ }^{79}$. La decisión de 1989, a pesar de ocurrir bajo la vigencia de la actual Constitución ${ }^{80}$, surgió dentro de un contexto que llevó la Enmienda

\footnotetext{
${ }^{72}$ Mandato de Seguridad MS 20.916. Supremo Tribunal Federal, Órgano juzgador: Pleno, Relator para la sentencia Min. Sepúlveda Pertenece, Fecha decisión: 11/10/1989, DJ 26/03/1993.

${ }_{73}$ Mandato de Seguridad MS 20.927. Supremo Tribunal Federal, Órgano juzgador: Pleno, Relator Min. Moreira Alves, Fecha decisión: 11/10/1989, DJ 15/04/1994.

${ }^{74}$ Mandato de Seguridad MS 26.602. Supremo Tribunal Federal, Órgano juzgador: Pleno, Relator Min. Eros Grau, Fecha decisión: 04/10/2007, DJ 17/10/2008.

${ }^{75}$ Mandato de Seguridad MS 26.603. Supremo Tribunal Federal, Órgano juzgador: Pleno, Relator Min. Celso de Mello, Fecha decisión: 04/10/2007, DJ 19/12/2008.

${ }^{76}$ Mandato de Seguridad MS 26.604. Supremo Tribunal Federal, Órgano juzgador: Pleno, Relator Min. Carmen Lucia, Fecha decisión: 04/10/2007, DJ 03/10/2008.

${ }_{77}$ Existen hipótesis excluyentes de infidelidad partidaria, como v.g. mudanza significativa de orientación programática del partido y persecución política dentro del partido que abandonó.

${ }_{78}$ Para un análisis más detenido de esta mutación constitucional, consulte: SANT’ANA Pedra (2008a), pp. 207-249.

${ }^{79}$ En verdad, el propio ámbito normativo influencia en la renovación de la composición de la Corte.

${ }^{80}$ A esto se suma que la decisión de 1989, que orientaba el razonamiento predominante hasta entonces, se basaba en un pleito ocurrido el 15/11/1986, o sea, antes de la Constitución brasileña vigente, promulgada el 05/10/1988.
} 
Constitucional No 25/1985 a revocar la hipótesis de pérdida del mandato por infidelidad partidaria en la Constitución pasada. Debe ser recordado que la fidelidad partidaria fue un instrumento utilizado por el gobierno militar para asegurar la mayoría en el Congreso Nacional brasileño. Antes de tal revocación, el partido en el poder utilizaba la fidelidad partidaria para v.g. no perder los parlamentarios "biónicos" - de sus votos- para el partido de la oposición.

Otro ejemplo de mutación constitucional ocurrió con el concepto de familia dado por la Constitución brasileña de 1967/1969 (ya no está en vigor), que decía que "la familia es constituida por el casamiento y tendrá derecho a la protección de los Poderes Públicos" (artículo 167 del texto constitucional de 1967 y artículo 175 del texto constitucional de 1969). Dentro de este concepto, no había la idea de protección a la situación de un hombre y una mujer que cohabitasen como cónyuges, sin ser casados. A pesar de la literalidad del dispositivo constitucional anteriormente citado, en su proceso de concretización, el Supremo Tribunal Federal entendió, en la sentencia del Recurso Extraordinario RE No $60.657 / \mathrm{GO}^{81}$ que, en razón de las mudanzas en las concepciones culturales y sociales brasileñas, el derecho debería también proteger la relación constituida a partir de la convivencia, bajo el mismo techo, de hombre y mujer no casados. Se puede decir que este hiato entre el texto constitucional -reciente en relación a estas decisiones del Supremo Tribunal Federal- y la realidad brasileña se debía, en gran parte, a que el referido texto constitucional haber sido otorgado de una manera dictatorial, y no discutido en una asamblea constituyente formada por legítimos representantes del pueblo.

Bajo la vigencia de la actual Constitución brasileña de 1988, el Supremo Tribunal Federal dictaminó la Arguiçãa de Descumprimento de Preceito Fundamental-ADPF No 132/RJ (Reclamación de Incumplimiento de Precepto Fundamental), donde se pleiteaba el reconocimiento de que el régimen jurídico de las uniones estables también se deba aplicar a las uniones homosexuales, a pesar del texto constitucional vigente establecer que, "para efecto de la protección del Estado, es reconocida la unión estable entre el hombre y la mujer como entidad familiar, debiendo la ley facilitar su conversión en casamiento" (artículo 226, $\mathbb{\$} 3^{\circ}$ ). El Abogado-General de la Unión se manifestó en el sentido de extraer de allí una norma más allá del que está expresamente escrito en el texto constitucional:

${ }^{81}$ Supremo Tribunal Federal. Segunda Turma. Rel. Min. Adalicio Nogueira. J. 20/11/1970. DJ 16/12/1970. 
Se puede afirmar que, a despecho de la Carta de 1988 no haber contemplado -de modo expreso- el tratamiento jurídico de las uniones homosexuales en el capítulo que dedica a la familia, la evolución y la complejidad de las relaciones humanas están por exigir al sistema jurídico respuestas adecuadas para la resolución de esas controversias, íntimamente ligadas al pleno ejercicio de los derechos humanos fundamentales. [...] La compresión del tema pasa, sin duda, por el análisis de los parámetros normativos ya existentes con relación al casamiento y la unión estable y de la concretización de los postulados constitucionales de la igualdad, de libertad y de la promoción de una sociedad libre de preconceptos. [...] Considerando, pues, que las relaciones afectivas, sean homosexuales o heterosexuales, son basadas en el mismo soporte fáctico, no hay razón -bajo pena de discriminación- para atribuirse a las mismas tratamiento jurídico diferenciado. [...] No hay esfuerzo hermenéutico, desasistido de preconcepto, capaz de encontrar justificativa plausible para ofrecer solución jurídica que trate de modo diferenciado los integrantes de uniones homoafectivas. Indudablemente, constituyen familia.

La Justicia Electoral ${ }^{82}$ ya consideraba como cónyuges, para efectos de la inelegibilidad establecida en el artículo $14, \$ 7^{\circ}$, de la Constitución brasileña, las personas del mismo sexo, bajo el fundamento de que, viviendo en estado de casadas, deben ser tratadas como si casadas fueran, no debiendo ser despreciado el principio de la igualdad.

Aunque un intervalo de poco más de veinte años de vigencia de la Constitución brasileña de 1988 no sea largo o suficiente para que sean identificadas muchas mudanzas significativas en la realidad social brasileña, es posible percibir la ocurrencia de algunas mutaciones constitucionales.

A partir de la observación de la jurisprudencia del Supremo Tribunal Federal brasileño, se puede verificar la ocurrencia de una interpretación evolutiva ${ }^{83}$,

${ }^{82}$ Tribunal Superior Electoral. Recurso Especial Electoral No 24.564, fallo publicado en sesión, el 01/10/2004: "Registro de candidato. Candidata al cargo de prefecto. Relación estable homosexual con la prefecta reelecta del municipio. Inelegibilidad. Art. 14, $\$ 7^{\circ}$, de la Constitución Federal. Los sujetos de una relación estable homosexual, a semejanza de lo que ocurre con los de relación estable, de concubinato y de casamiento, se someten a la regla de inelegibilidad prevista en el art. $14, \$ 7^{\circ}$, de la Constitución Federal".

${ }^{83}$ A este respecto, véase: SANT'Ana Pedra (2008d), pp. 187-202, donde es analizada la evolución de la jurisprudencia del Supremo Tribunal Federal brasileño envolviendo (1) los derechos fundamentales de extranjeros no residentes, (2) el concepto de hogar, (3) la progresión del régimen de cumplimiento de la pena para los condenados por crímenes horrendos, (4) la extradición y conmutación de la pena de prisión perpetua, y (5) el mandato de injunción. 
con la reconstrucción del derecho constitucional dinámicamente, de acuerdo a las exigencias de la realidad social cambiante ${ }^{84}$. André Ramos Tavares coloca que la interpretación evolutiva se muestra extremadamente adecuada a las Constituciones que, como la brasileña y la mayoría de las constituciones actuales, contemplan en sí finalidades distintas, absolutamente diversas ${ }^{85}$. De esa forma, la preferencia por una u otra depende del momento histórico vivido.

\section{CONCLUSIÓN}

La mutación constitucional (Verfassungswandlungen) consiste en un proceso informal de alteración de la Constitución, que no se encuentra previsto expresamente en el texto constitucional. Tal cambio informal ocurre mediante el desenvolvimiento de la norma, aunque el texto constitucional permanezca el mismo.

El fenómeno de la mutación constitucional es una constante en la vida de los Estados y ocurre porque la significación de la Constitución no es dada de antemano, ya que depende del contexto en el cual es concretizado. El sentimiento constitucional presente en cada momento vivido pasa a permear la realización de la Constitución, y la naturaleza dinámica de la Constitución, como organismo vivo que es, permite que ella pueda acompañar la evolución de las circunstancias sociales, políticas y económicas.

Actualmente apartada de su pasado preponderantemente político, la mutación constitucional dejó de funcionar como una influencia del mundo fáctico sobre la Constitución y se tornó legítima en la medida en que se mantiene en los marcos normativos establecidos por la Constitución.

El estudio permitió constatar la relación existente entre concreción y mutación constitucional. La comprensión de la teoría de la concreción es muy útil para entender el fenómeno de la mutación constitucional, pues el análisis de los procesos informales de cambios en la Constitución y su relación con los cambios en la realidad deben ser hechas tomando en cuenta la estructura de la norma constitucional.

A pesar de que las circunstancias fácticas integraren la concepción de la norma, esto no significa afirmar que la Constitución deba sucumbir a las fuerzas de

${ }^{84}$ Sant'Ana Pedra (2009), pp. 395-414.

${ }^{85}$ Ramos Tavares (2007), p. 86. 
las circunstancias de la realidad. La idea de Constitución normativa exige que las normas constitucionales sean responsables por conformar la realidad. En ese sentido, es indispensable aproximar el mundo fáctico y el mundo normativo a fin de que no haya cualquier mitigación a la supremacía de la Constitución, tomando en cuenta que lo fáctico no puede superar lo normativo.

\section{Bibliografía}

Adeodato, João Maurício (2006): Ética e retórica (São Paulo, Saraiva).

Afonso DA SiLVA, Virgílio (2009): Direitos fundamentais (São Paulo, Malheiros).

Alflen da Silva, Kelly Susane (2000): Hermenêutica jurídica e concretização judicial (Porto Alegre, Sergio Antonio Fabris).

Almeida Filho, Agassiz (2008): Introdução ao direito constitucional (Rio de Janeiro, Forense).

Ávila, Humberto (2007): Teoria dos principios (São Paulo, Malheiros).

Bonavides, Paulo (2003): Curso de direito constitucional (São Paulo, Malheiros).

Barros de Carvalho, Paulo (2006): Direito tributário (São Paulo, Saraiva).

Cunha Ferraz, Anna Candida da (1986): Processos informais de mudança da Constituição (São Paulo, Max Limonad).

DwOrkIN, Ronald (1978): Taking rights seriously (Cambridge, Harvard University).

ENGISCH, Karl (2004): La idea de concreción en el derecho y en la ciencia jurídica actuales (Traducc. Juan José Gil Cremades, Granada, Comares).

FABRIZ, Daury César (2006): "A crise do direito fundamental ao trabalho no início do século XXI", en Revista de Direitos e Garantias Fundamentais (Año 1, No 1), pp. 15-38.

Ferreira Mendes, Gilmar; Mártires Coelho, Inocêncio; Gonet Branco, Paulo Gustavo (2008): Curso de direito constitucional (São Paulo, Saraiva).

GadAmer, Hans-Georg (1999): Verdade e método (Traducc. Flávio Paulo Meurer, Petrópolis, Vozes.

Gomes Canotilho, José Joaquim (2002): Direito constitucional e teoria da constituição (Coimbra, Almedina).

Grau, Eros Roberto (2006): Ensaio e discurso sobre a interpretaçãolaplicação do direito (São Paulo, Malheiros). 
Guastini, Riccardo (2005): Das fontes às normas (Traducc. Edson Bini, São Paulo, Quartier Latin).

Hesse, Konrad (1992): Escritos de derecho constitucional (Traducc. Pedro CruZ Villalón, Madrid, Centro de Estudios Constitucionales).

LAMmÊGo Bulos, Uadi (1997): Mutação constitucional (São Paulo, Saraiva).

LARENZ, Karl (1997): Metodologia da ciência do direito (Traducc. José LAMEGO, Lisboa, Calouste Gulbenkian).

MÜlLER, Friedrich (2006): Métodos de trabajo del derecho constitucional: fundamentación general de una concepción de los métodos en el trabajo jurídico (Traducc. Salvador Gómez de Arteche y Catalina, Madrid, Marcial Pons).

Müller, Friedrich (2007): O novo paradigma do direito (Traducc. Dimitri DImoulis, Gilberto Bercovici, Peter Naumann, Rodrigo Mioto dos Santos, Rossana Ingrid Jansen dos Santos, Tito Lívio Cruz Romão y Vivianne Geraldes Ferreira, São Paulo, RT).

MülleR, Friedrich (2008): Teoria estruturante do direito (Traducc. Peter NAUmann y Eurides Avance de Souza, São Paulo, RT).

MÜlleR, Friedrich (1989): "Tesis acerca de la estructura de las normas jurídicas", Traducc. Luis Villacorta Mancebo, en Revista Española de Derecho Constitucional n. 27, pp. 111-126.

Neves, Marcelo (2007): A constitucionalização simbólica (São Paulo, Martins Fontes).

QueIroz, Cristina (2000): Interpretação constitucional e poder judicial (Coimbra, Coimbra).

Ramos Tavares, André Ramos (2008): "A teoria da concretização constitucional", em Revista Brasileira de Estudos Constitucionais 7, pp. 13-30.

Ramos Tavares, André Ramos (2007): Curso de direito constitucional (São Paulo, Saraiva).

Ramos Tavares, André Ramos (2006): Fronteiras da hermenêutica constitucional (São Paulo, Método).

Ribeiro Bastos, Celso (2002): Hermenêutica e interpretação constitucional (São Paulo, Celso Bastos).

Ribeiro Bastos, Celso; Meyer-Pflug, Samantha (2007). "A interpretação como fator de desenvolvimento e atualização das normas constitucionais", en Afonso Da SiLVA, Virgílio (org.) (2007): Interpretação constitucional (São Paulo, Malheiros). 
Sant'Ana Pedra, Adriano (2005): A Constituição viva (Belo Horizonte, Mandamentos).

Sant'Ana Pedra, Adriano (2008a): “A construção judicial da fidelidade partidária no Brasil”, en Revista Brasileira de Estudos Constitucionais 6, pp. 207-249.

SAnt'Ana Pedra, Adriano (2008b): "A importância do concreto no processo interpretativo dos direitos fundamentais", en Depoimentos - Revista de Direito da FDV 14, pp. 9-12.

Sant'Ana Pedra, Adriano (2008c): "A natureza principiológica do duplo grau de jurisdição", en Revista de Direito Administrativo 247, pp. 13-30.

Sant'Ana Pedra, Adriano (2008d): "Evolução de direitos e garantias fundamentais e vedação de retrocesso: uma abordagem da jurisprudência do STF nos vinte anos da Constituição brasileira", en Homem De Siqueira, Julio Pinheiro Faro; Costa Teixeira, Bruno; Castello Miguel, Paula (coord.) (2008): Uma homenagem aos 20 anos da Constituição brasileira (Florianópolis, FDV/Boiteux).

Sant'Ana Pedra, Adriano (2011): "La inelegibilidad del analfabeto en Brasil: por una lectura más democrática”, en Estudios Constitucionales (Año 9, No 1), pp. 227-244.

Sant'Ana Pedra, Adriano (2009): Mutación constitucional de los derechos fundamentales y prohibición de retroceso, en Memoria del X Congreso Iberoamericano de Derecho Constitucional (Lima, Ideosa).

Streck, Lenio Luiz (2004): "A diferença ontológica (entre texto e norma) como blindagem contra o relativismo no processo interpretativo: uma análise a partir do 'ontological turn' ”, en Revista Brasileira de Estudos Políticos 89, pp. 121-160.

TRIBE, Laurence (1986): Constitutional choices (Massachusetts, Harvard).

VIGO, Rodolfo Luis (2004): Interpretación constitucional (Buenos Aires, Lexis Nexis/Abeledo-Perrot).

WRÓBLEWSKI, Jerzy (1985): Constitución y teoría general de la interpretación jurídica (Traducc. Arantxa Azurza, Madrid, Civitas). 